\title{
Self moral e identidade moral: integração entre perspectivas
}

\author{
Marco Antonio Morgado da Silva ${ }^{a *}$ (]) \\ Ulisses Ferreira de Araújob ${ }^{b}$
}

\author{
aUniversidade de São Paulo, Faculdade de Educação. São Paulo, SP, Brasil \\ bUniversidade de São Paulo, Escola de Artes, Ciências e Humanidades e Faculdade de Educação. São Paulo, SP, Brasil
}

\begin{abstract}
Resumo: As teorias sobre self (si mesmo) moral formuladas por Blasi, Damon e Colby constituíram um ponto de inflexão no campo da psicologia moral, até então marcado pelo predomínio da perspectiva de Kohlberg. A proposição de que a integração entre a moralidade e o self ou a identidade é um componente fundamental do funcionamento moral inaugurou uma nova corrente de estudos permeada por diferentes perspectivas sobre o funcionamento do self moral e sua relação com os juízos, emoções e ações morais. O presente artigo sistematiza perspectivas acerca dos constructos self moral e identidade moral, evidenciando suas diferenças, convergências e lacunas. Ademais, propõe uma integração entre essas perspectivas e faz aportações que indicam a possibilidade de ampliação do espectro de compreensão sobre esses constructos.
\end{abstract}

Palavras-chave: self moral, valores, identidade moral.

\section{Introdução}

Objeto de estudo da filosofia desde a Grécia Antiga, a moral, a partir do século XX, passa a ser tematizada por cientistas interessados em compreender os mecanismos psicológicos subjacentes às condutas morais. As formulações teóricas, bem como os métodos desenvolvidos por Lawrance Kohlberg (1989), no âmbito da psicologia cognitivo-desenvolvimental, constituíram um marco nos estudos inscritos no campo da psicologia moral. Os diversos estudos desenvolvidos nessa perspectiva, conforme revisão feita por Moshman (2011), elegeram o juízo moral como unidade privilegiada do funcionamento moral, evidenciando a existência de estágios de desenvolvimento do juízo moral e advogando que as condutas morais resultariam, em grande medida, da capacidade do sujeito compreender, de modo autônomo, a importância de princípios morais universais, como a justiça.

A despeito da predominância dessa perspectiva, a partir da segunda metade da década de 1980 alguns estudiosos passaram a explorar e a explicar a moralidade por meio de outras perspectivas teóricas e metodológicas, muitos dos quais motivados pelo reconhecimento de lacunas e fragilidades identificadas no paradigma kohlberguiano. Algumas dessas críticas dirigiram-se à subordinação do funcionamento moral ao desenvolvimento de estruturas cognitivas (Turiel, 1989), bem como à primazia conferida à razão no funcionamento moral em detrimento dos sentimentos (Gilligan, 1985;

*Endereço para correspondência: marcomorgado.s@gmail.com
Hoffman, 1990). Outras críticas referiam-se ao fato de que as pesquisas de Kohlberg aferiam um juízo moral abstrato, desvinculado das situações concretas em que vivem os sujeitos, de seus contextos culturais e também dos valores e necessidades que constituem sua pessoalidade (Blasi, 1983; Colby \& Damon, 1992; Damon, 1984; Turiel, 1989, 1996; Nisan, 1993; Nucci, 1996). Tais críticas vieram acompanhadas das constatações de que indivíduos de reconhecido compromisso moral nem sempre apresentavam níveis sofisticados de juízo moral (Colby \& Damon, 1992) e de que um juízo abstrato pautado em critérios de justiça muitas vezes não se traduzia em ação (Blasi, 1983) ou mesmo não conservava a mesma consistência quando submetido a diferentes conteúdos e contextos (Turiel, 1989, 1996; Nisan, 1993; Nucci, 1996). Argumentava-se, ademais, que nem razão nem emoção, sozinhas, conseguiam explicar suficientemente a ação, a coerência e o compromisso morais (Blasi, 1984; Colby \& Damon, 1992).

É nesse contexto que os trabalhos de Willian Damon (1984), os de sua parceria com Anne Colby (Colby \& Damon, 1992) e os de Augusto Blasi (1984) deflagram uma nova corrente de pesquisas no campo da psicologia moral, ao proporem a tese de integração da moral ao self ou identidade ${ }^{1}$ como componente

O self é definido pelos autores como representação de si ou autoconceito. É a base para a constituição da identidade pessoal. A identidade, por sua vez, é conceituada como o conjunto de constructos (traços, objetivos, crenças etc.) que compõem o núcleo do self, os quais lhe conferem unidade e são mobilizados como centrais na explicação do sujeito sobre si mesmo. Assim, self moral e identidade moral são conceitos sobrepostos e por vezes usados indistintamente, contudo o segundo pode ser empregado 
fundamental do funcionamento moral e importante chave explicativa para a lacuna entre juízo e ação moral.

As teorias desses autores constituíram um ponto de inflexão no paradigma consolidado por Kohlberg, inaugurando um campo de estudos permeado por diferentes abordagens e perspectivas sobre o funcionamento do self moral e sua relação com os juízos, emoções e ações morais. Revisões da literatura (Hardy \& Carlo, 2011; Hertz \& Krettenauer, 2016; Jennings, Mitchell, \& Hannah, 2015) têm indicado os principais achados de investigações empíricas e a existência de diferentes enfoques teóricos e metodológicos, porém sem se debruçar sobre a sistematização das perspectivas teórico-metodológicas que compõem esse campo de estudos e apontar as possibilidades de integração entre elas.

O objetivo do presente artigo é sistematizar perspectivas acerca dos constructos self moral e identidade moral, evidenciando suas diferenças, convergências e lacunas, bem como indicar possibilidades de integração entre essas perspectivas e propor complementações que possibilitem aos estudos sobre self e identidade moral a ampliação do espectro de compreensão sobre o objeto.

Iniciaremos dando destaque às teorias de Damon, Colby e Blasi. Em seguida, sistematizamos diferentes perspectivas conceituais e abordagens teórico-metodológicas acerca da constituição e do funcionamento do self moral para, então, propor uma perspectiva integradora sobre self moral e tecer as considerações finais.

\section{As teorias de Willian Damon, Anne Colby e Augusto Blasi}

O psicólogo Willian Damon foi um dos pioneiros na proposição da teoria de que a moral e o self poderiam operar de modo coordenado no funcionamento psíquico. Em pesquisa longitudinal sobre o desenvolvimento da compreensão de si da infância à adolescência, Damon (1984) constatou que o self e a moral são sistemas conceituais distintos, que se encontram separados em dados momentos do desenvolvimento; mas que, na transição da infância para a adolescência (ao redor dos 12 anos de idade), passa a ocorrer, em graus variados, uma integração e influência recíproca entre tais sistemas, momento em que o sujeito passa a definir a si mesmo não apenas se referindo a atributos físicos e ações materiais, mas também a características, objetivos e preocupações morais.

A partir dessa pesquisa, o autor passa a afirmar que a percepção do indivíduo acerca da moral em si mesmo influencia o juízo e a conduta moral e argumenta que aquele indivíduo para quem a moral é um aspecto central de sua compreensão de si (identidade moral)

em distinção ao primeiro para destacar a centralidade que valores morais assumem no self do sujeito. tenderá a identificar as questões morais em uma gama maior de situações em sua vida e tenderá a acreditar que o seu papel, enquanto indivíduo, é agir moralmente, pois se perceberá como um agente moral responsável por isso.

Anos depois, Damon empreende uma célebre pesquisa em parceria com Anne Colby (Colby \& Damon, 1992), com a intenção de saber o que motivava adultos reconhecidos por dedicarem suas vidas a projetos sociais. Os autores constataram que, na perspectiva dessas pessoas, não havia uma renúncia aos propósitos pessoais em favor do compromisso moral, pois as preocupações morais ocupavam posição central na representação que faziam de si, de tal forma que a realização da moral em suas vidas era indissociável da sua realização pessoal. Com essa pesquisa os autores concluíram que, para a maioria das pessoas, a moral e o self estão apenas parcialmente integrados, ora manifestando unidade, ora conflito. As condutas que contrariam suas crenças morais ocorreriam justamente por essas últimas não estarem coordenadas (ou integradas) com o self. Já o grau de unidade entre moral e self encontrado nos exemplares morais foi considerado um fenômeno raro, consolidando-se apenas na fase adulta, sendo a chave do extraordinário compromisso moral que manifestam (Colby \& Damon, 1992).

Outro estudioso cujas publicações causaram um abalo no paradigma kohlberguiano foi Augusto Blasi (1984, 1995, 2004), que confere à identidade moral um papel relevante no funcionamento e nas ações morais. Em seu modelo teórico, denominado self model of moral functioning, Blasi (1984) admite que critérios de raciocínio moral são o primeiro fator que determina a ação moral, pois permitem ao sujeito interpretar se deve ou não agir moralmente. No entanto, o autor pondera que a concretização da ação moral depende de escolhas morais pessoais, que ocorrem no âmbito de um julgamento moral sobre uma ação real com a qual a pessoa está envolvida, e não de escolhas no interior de raciocínios morais abstratos e extrínsecos ao sujeito. Para ele, entre o juízo abstrato e a ação atua uma segunda ordem de raciocínio, que ele denomina julgamento de responsabilidade pessoal, que determina em que medida aquilo que é compreendido como moralmente bom é também importante e necessário para si mesmo a ponto de ser sentido como uma responsabilidade pessoal em agir. Disso segue-se que o julgamento de responsabilidade e o sentimento de que uma ação é necessária dependerão de como o self está constituído, sendo, destarte, resultado da integração da moral ao self.

Quanto à concretização da ação, o autor considera que a identidade moral tenderá a determiná-la devido à tendência que todos os indivíduos possuem em preservar uma coerência com sua própria identidade. Nesse sentido, agir moralmente é preservar uma identidade para a qual crenças e ideais morais são centrais e não 
o fazer significa violar a si mesmo, trair os próprios princípios (Blasi, 1984).

De acordo com Blasi (1995, 2004), a moral integra-se ao self por meio de sua integração aos sistemas motivacionais e emocionais dos indivíduos. Em sua concepção, os indivíduos vinculam-se a determinados objetos de desejo ou interesse, identificando-se, querendo ser e agir como eles. Esses objetos de interesse, que se tornam valores para o sujeito, podem ou não expressar conteúdos morais e passarão a ser organizados no self em sua relação com outros valores e de acordo com a maior ou menor preferência do sujeito. Assim, o autor propõe que os graus de integração de um elemento ao self dependerão I) da coordenação com outros elementos ou subsistemas do self e II) da forma como se posiciona em sua hierarquia de preferências. A esse respeito o autor acrescenta que, para algumas pessoas, valores morais estão fortemente integrados a quem são e a quem querem ser, sendo preferíveis a outros tipos de valores na determinação de suas ações. Essas pessoas possuem uma identidade moral.

Sobre essa proposição teórica, o autor ressalva que o reconhecimento de que alguns valores ou atributos pessoais são mais centrais para a unidade e essência de si mesmo é um mecanismo que não é operado por todas as pessoas de modo igual, que não ocorre em crianças e que é observado apenas em poucos adolescentes. Além disso, salienta que apenas a partir de jovens adultos é possível identificar a constituição de uma identidade moral mais consolidada, a comandar um fluxo coerente e mais contínuo de ações e compromissos morais. $\mathrm{O}$ autor, porém, sublinha que a integração da moral à identidade não é o único fator determinante para a ação moral (Blasi, 1995, 2004).

\section{A identidade moral como integração entre interesses pessoais e comunitaristas}

Inspirados nas obras de Blasi e nas de Colby e Damon, Frimer e Walker, junto a colaboradores (Frimer \& Walker, 2009; Frimer, Walker, Dunlop, Lee, $\&$ Riches, 2011) desenvolveram um modelo empírico para investigar a integração da moral ao self e o papel da centralidade moral na motivação de ações morais. A premissa da qual partem os autores é que o self pode ser movido por duas classes de interesses: a) interesses pessoais, que visam satisfazer necessidades individuais e manifestam valores como poder, realizações, dominação, bens materiais e conquistas; e b) interesses comunitaristas (ou morais), que visam promover interesses do outro e manifestam valores como benevolência, preocupações interpessoais, justiça social e preservação ecológica. Esses dois tipos de interesse geralmente se encontram dissociados ou em conflito, mas podem se integrar quando o indivíduo passa a admitir interesses comunitaristas como parte de seus interesses pessoais.
A fim de validar seu modelo empírico, os autores desenvolveram uma série de pesquisas com jovens universitários, combinando instrumentos qualitativos (entrevistas sobre a representação de si) e quantitativos (medidas sobre a centralidade de valores e sobre a tendência a comportamentos pró-sociais). As pesquisas revelaram que os valores comunitaristas mobilizados nas entrevistas, assim como a capacidade de coordenar valores pessoais e comunitaristas, previram positivamente comportamentos pró-sociais, enquanto valores "autointeressados" previram negativamente esse tipo de comportamento (Frimer \& Walker, 2009). Além disso, indivíduos considerados moralmente exemplares relacionaram interesses pessoais e morais nos significados atribuídos a si mesmos e demonstraram mais valores pessoais e comunitaristas como parte de suas motivações em comparação com um grupo controle (Frimer et al., 2011).

A partir desses achados, Frimer, Walker e colaboradores não apenas provêm sustentação empírica às teorias de self moral, como passam a propor um modelo explicativo sobre a integração da moral ao self no desenvolvimento. Segundo esse modelo, ao menos até o início da adolescência, os interesses pessoais e comunitaristas que motivam o self costumam estar segregados. Mas, na medida em que cada um desses motivadores torna-se mais elaborado e cada vez mais central para o indivíduo, os dois sistemas motivacionais podem entrar em conflito e produzir uma crise - para a qual uma das possíveis soluções adaptativas é o processo de integração. Na concepção dos autores, essa integração pode ocorrer apenas a partir da adolescência, mas é somente no final dessa fase e no início da idade adulta que se torna mais comum, podendo ocorrer em qualquer momento da vida, embora a centralidade dessa integração seja um fenômeno extraordinário. Para eles, uma vez que a integração ocorre, ela tende a se manter estável.

\section{A identidade moral como acessibilidade de esquemas morais no self}

A identidade moral, na perspectiva de Lapsley e Narvaez (2004; Lapsley \& Hill, 2009), pode ser concebida como a acessibilidade crônica de esquemas morais no self. Em concordância com Blasi (2004), os autores propõem que constructos morais que são essenciais, centrais e importantes para a identidade pessoal seriam aqueles cronicamente acessíveis e facilmente ativados para interpretar a paisagem social. Tais constructos, para eles, podem ser sintetizados no conceito de esquema.

Segundo os autores, esquemas são estruturas cognitivo-afetivas de organização do pensamento construídas nas nossas experiências sociais, que representam vários aspectos da realidade pessoal e social; direcionam e filtram a percepção, a memória e as reações afetivas. Alguns exemplos de esquemas são 
os conceitos, episódios, scripts de ação e protótipos. Os esquemas morais, nesse sentido, incluiriam protótipos sobre o que significa ser uma pessoa moral, scripts de ações morais, representações de experiências morais significativas, entre outros exemplos (Hardy \& Carlo, 2011; Lapsley \& Narvaez, 2004).

De acordo com Lapsley e Narvaez (2004), os esquemas são construídos mediante um processo de socialização que inclui a repetição de experiências e instruções, treinamentos intencionais e comportamentos rotinizados. Quanto mais frequente o acesso a (ou o uso de) determinado esquema, mais ele se tornará cronicamente acessível na organização da personalidade, sendo, por isso, responsável por direcionar nossa atenção a certos aspectos de nossa experiência ao invés de outros e por favorecer o desenvolvimento de rotinas de comportamento e de ações imediatas ou automáticas. Consoante os autores, os esquemas morais operam, via de regra, de modo tácito e automático no funcionamento moral - ainda que sua construção frequentemente passe pela consciência.

A importância e a acessibilidade de esquemas morais para o self têm demonstrado ser componentes da identidade moral e preditoras de atitudes e comportamentos morais, conforme revelam diferentes estudos (Aquino, Freeman, Reed, Felps, \& Lim, 2009; Hertz \& Krettenauer, 2016; Lapsley \& Stay, 2014; Reed, Kay, Finnel, Aquino, \& Levy, 2016).

\section{A identidade moral como um tipo de identidade social importante para o self}

Aquino e Reed (2002) desenvolveram um modelo metodológico amplamente utilizado nos últimos anos no estudo da identidade moral (Hertz \& Krettenauer, 2016). Os autores partem da concepção de que existem diversas identidades sociais que constituem o self das pessoas, as quais se organizam em uma estrutura única de conhecimento na memória, denominada esquema de self social (a representação de si no mundo social). As identidades sociais que construímos são relativas ao senso de pertença a um grupo, ao papel que desempenhamos e ao tipo de pessoa que desejamos retratar aos outros e a nós mesmos. Partindo dessa premissa, os autores conceituam a identidade moral como um tipo de identidade social construída ao redor de esquemas de self moral, entendidos como as concepções do indivíduo acerca do que significa ser uma pessoa moral e do tipo de pessoa moral que se deseja ser para si e para os outros (Aquino \& Reed, 2002), além de seus valores e scripts de comportamento (Aquino et al., 2009).

No modelo metodológico de Aquino e Reed (2002), a definição de identidade moral baseia-se em um tipo específico de esquema, os traços morais que a pessoa elege para definir a si própria (ser justo, generoso etc.), e é determinada pela centralidade que o indivíduo outorga à identidade moral em seu autoconceito. Disso se desdobra a hipótese de que quanto maior é a importância que o indivíduo atribui aos traços morais que definem sua identidade moral, maior é a possibilidade de que esses traços sejam acionados em diferentes situações e estejam associados aos juízos e ações morais.

É com base nessas premissas que os autores constroem seu método de investigação intitulado self importance of moral identity, com vistas a: a) medir a importância pessoal da identidade moral por meio da importância que os sujeitos atribuem a um conjunto de traços morais; e b) demonstrar que a identidade moral pode prever comportamentos e raciocínios morais (Aquino \& Reed, 2002).

Os resultados dessa pesquisa revelaram uma correlação positiva entre identidade moral e relatos de ações morais, sendo corroborados por mais de 60 estudos que adotaram o mesmo instrumento de medida para identidade moral (Hertz \& Krettenauer, 2016). Além disso, estudos tributários dessa abordagem (Lapsley \& Stay, 2014; Reed et al., 2016) demonstraram que pessoas com identidade moral são mais propensas a doarem seu tempo para causas sociais e são mais empáticas.

Por outro lado, Hertz e Krettenauer (2016) sinalizam que a identidade moral, no âmbito dessas pesquisas, não indicou ser um extraordinário previsor de ações morais em comparação às medidas para juízo e empatia. Os autores discutem que o fato de o método restringir a identidade moral a um conjunto de traços morais predefinidos impossibilita afirmar que os resultados explicam categoricamente o funcionamento da identidade moral.

Lançando mão dos mesmos pressupostos e do mesmo instrumento de medida sobre identidade moral, Aquino, Reed e colaboradores (Aquino et al., 2009) desenvolveram 4 novos estudos pautados em três premissas: I) a identidade moral é uma fonte motivacional da ação moral, porque as pessoas desejam manter uma autoconsistência (Blasi, 1984); II) as pessoas manejam múltiplas facetas de suas identidades, mas apenas algumas delas se encontram salientes no autoconceito a qualquer momento; e III) fatores situacionais podem ativar a identidade moral ou outras facetas de suas identidades, aumentando ou diminuindo a acessibilidade corrente de esquemas morais no autoconceito.

Os resultados revelaram que: a) na medida em que a acessibilidade corrente da identidade moral aumenta, também aumentam as intenções de realizar um comportamento pró-social, ao passo que a diminuição da acessibilidade da identidade moral aumenta disposições em agir de modo egoísta; b) a influência da identidade moral no comportamento é contingente à saliência (centralidade) da identidade moral no autoconceito em relação a outras identidades; e c) fatores situacionais 
podem gerar comportamentos voltados aos interesses pessoais mesmo entre pessoas para as quais a identidade moral é central (Aquino et al., 2009).

Acerca dessas últimas considerações, cumpre advertir que o fato de o sujeito agir em consonância com interesses pessoais em função de um contexto que suscita esse tipo de conduta não significa que a identidade moral deixou de ter centralidade para ele, pois a referida pesquisa não examina o quão estável pode ser a identidade moral no curso do tempo.

\section{A representação moral de si na narrativa autobiográfica}

Para diversos autores, uma das formas pela qual conteúdos morais se integram à representação de si é por intermédio da representação de eventos moralmente relevantes em suas memórias e narrativa autobiográficas. Uma vez que a narrativa de vida é uma expressão basilar da construção da identidade (McAdams, 2009), alguns autores advogam que ter uma identidade moral supõe, entre outras coisas, possuir uma narrativa autobiográfica em que representações morais sobre si no passado, presente e futuro comparecem como organizadores fundamentais do self (Hardy \& Carlo, 2011; Lapsley, 2010; Lapsley \& Narvaez, 2004; McAdams, 2009; Pratt, Arnold, \& Lawford, 2009).

Entre os conteúdos morais que constituem as memórias e narrativas autobiográficas, identificamos na literatura a menção à representação de eventos morais ou imorais dos quais o indivíduo participou, como agente ou que observou na figura de espectador (Hardy \& Carlo, 2011; Lapsley, 2010). A realização de ações morais, no que lhe concerne, tem demonstrado cumprir um importante papel na constituição do self e da identidade moral ao se tornar parte das memórias e narrativas autobiográficas (Cox \& McAdams, 2012; Pratt, et al., 2009; Yates \& Youniss, 1996). Já com relação às ações imorais, Lapsley (2010) sublinha que uma experiência de falha moral intencional é tão formativa quanto a realização de ações pró-sociais, uma vez que, ao narrar um malfeito moral, o sujeito submete essa experiência a um procedimento reflexivo cuja consequência pode ser a ressignificação de si como um agente moral e a estruturação de esquemas morais sobre como se deve e não se deve agir em relação ao outro.

Além das experiências pessoais moralmente significativas, alguns autores mencionam que a representação de quem a pessoa deseja ser no presente e no futuro (ideal de self), bem como de seus objetivos e projeto de vida, é um componente importante da narrativa autobiográfica e da identidade (McAdams, 2009; Hardy \& Carlo, 2011), estando correlacionada a comportamentos altruístas, projetos de vida com compromisso social e senso de responsabilidade social (Hardy, Walker, Olsen, Woodbury, \& Hickman, 2014; Malin, Ballard, \& Damon, 2015; Pratt, et al., 2009).
Lapsley (2010) e Lapsley e Narvaez (2004), ao tematizarem a construção de esquemas morais que constituirão as memórias e narrativas autobiográficas, sugerem que as representações de eventos morais na forma de memórias autobiográficas atuam como precursoras do desenvolvimento de uma personalidade moral e têm sua origem nos primeiros diálogos com cuidadores, quando esses auxiliam as crianças a revisar, estruturar e consolidar memórias de maneira semelhante a um roteiro, podendo estruturar eventos de forma narrativa. Lapsley (2010) salienta que a fonte de internalização desses esquemas morais na personalidade decorre do afeto positivo compartilhado com os cuidadores e das experiências agradáveis relativas a esses esquemas (rotinas, por exemplo), que fazem com que a criança deseje cumprir com as expectativas relativas às normas, às demandas e aos valores de seus cuidadores para serem dignas de seu afeto e o retribuir. Para o autor, é nesse momento que surgem as primeiras noções sobre o que significa ser um bom garoto ou uma boa garota em termos morais.

\section{O self moral como um sistema dinâmico de valores}

Nisan (1993, 2004) e Araújo (2007) são dois autores cujos modelos teóricos e metodológicos lançam luz sobre o caráter dinâmico do funcionamento do self moral no interior de contextos reais e cambiantes.

Em seu modelo teórico e estudos empíricos, Mordecai Nisan $(1993,2004)$ adverte que na configuração do self ou identidade moral comparecem não apenas considerações morais, mas também necessidades, projetos e compromissos pessoais de outra ordem, com os quais o sujeito lidará e que exercem igual influência sobre as ações. Conforme suas pesquisas demonstram, ainda que um sujeito julgue uma decisão como moralmente correta e preferível em comparação com outra, poderá optar por não a realizar, caso a segunda decisão represente uma necessidade ou projeto de grande valor pessoal. Nesse sentido, o autor assinala que o fato de um conteúdo moral ser valorizado pelo sujeito não significa que este agirá sempre em correspondência com esse conteúdo moral, pois diante de cada situação entra em jogo um conjunto específico de valores que conformam um arranjo particular para lidar com ela. O que definirá qual dos valores será traduzido em ação concreta é o dano que sua violação acarretaria ao equilíbrio da identidade em um momento e situação específicos. Isso significa que um valor que predomina como motivador moral em dada situação pode perder importância diante de uma situação diferente, caso outros valores, desejos e interesses sejam mais relevantes para a manutenção do equilíbrio da identidade.

O conceito de equilíbrio da identidade é empregado por Nisan (1993) não apenas para se referir a uma tendência da identidade em preservar uma imagem positiva de si, 
mas também a um mecanismo de funcionamento da identidade com vistas a equilibrar valores e necessidades conflitantes. Tal premissa é confirmada por outros estudos, sendo nomeada de licença moral em alusão à concessão que a pessoa confere a si mesma para não agir moralmente (Hertz \& Krettenauer, 2016).

Outro pesquisador cujo modelo teórico nos auxilia a dimensionar a complexidade e o dinamismo do funcionamento moral é Ulisses Araújo (2007). O modelo teórico sobre o sistema de valores elaborado por Araújo adota como ponto de partida o referencial piagetiano sobre a construção psicológica de valores, segundo o qual valores são construídos com base na projeção afetiva que o sujeito faz sobre o objeto (pessoas, situações etc.) (Piaget, 1953/2014).

Consoante Araújo (2007), a construção do sistema de valores que se integra ao self conta com duas variáveis de domínio afetivo: a valência (positiva ou negativa) e a intensidade das projeções afetivas. Se a projeção afetiva sobre uma pessoa, uma situação ou uma ideia, por exemplo, for positiva, a tendência é que o sujeito construa um valor positivo sobre o objeto. Em contrapartida, sendo a projeção de afetos negativa, a pessoa construirá um contravalor. Na medida em que os valores e contravalores são construídos com base na ação projetiva de afetos, esses passam a se organizar em um sistema integrado ao self, situando-se mais ao centro ou à periferia desse sistema, dependendo da intensidade de sentimentos que acompanham a construção dos valores. A construção de valores de caráter moral ocorrerá caso o objeto de projeções afetivas positivas expresse um conteúdo moral perceptível e intelectualizado pelo sujeito.

Acerca do caráter dinâmico e complexo do sistema de valores, Araújo (2007) aponta que as diferentes situações de caráter moral com as quais nos deparamos são compostas de diferentes conteúdos, pessoas e circunstâncias que interagem e dinamizam nosso sistema de valores, de tal modo que um mesmo valor pode ser mais central ou mais periférico no self em relação a outros valores, dependendo da circunstância, dos conteúdos e das pessoas com os quais se vincula. Ademais, com o passar dos anos, em decorrência de novas experiências vividas pelo sujeito, um valor pode ganhar ou perder valência e com isso se reposicionar no sistema de valores.

Ainda no contexto desse marco teórico, Araújo (2007) enfatiza que junto às considerações de ordem moral há aspectos cognitivos, afetivos, sociais, além de disposições e necessidades biológicas, que constituem o sujeito psicológico e que exercem influência sobre os pensamentos, sentimentos e ações morais. Para o autor, é devido ao arranjo complexo do sistema de valores e à sua interação com outros sistemas do self que não é possível determinar com assertividade qual será a conduta moral de um indivíduo, mas tão somente falar em maior ou menor probabilidade em função da maior ou menor centralidade de um valor para a identidade.

\section{Uma perspectiva integradora para o estudo do self moral}

As formulações teóricas e os estudos empíricos que abordamos nas seções pretéritas denotam que o self moral é um fenômeno complexo, que se manifesta de diferentes maneiras e cujo funcionamento pode ser apreendido por diferentes perspectivas. A despeito de suas particularidades, não se tratam de perspectivas excludentes. Sua circunscrição ao marco construtivista e à psicologia cognitiva, bem como seu ancoramento nas teorias de Blasi, Damon e Colby, autoriza-nos a articulá-los como aportes complementares. A seguir faremos algumas considerações no sentido de apontar lacunas, sínteses, possibilidades de integração e propor complementações que possibilitem aos estudos sobre self moral buscarem ampliar o espectro de compreensão sobre o objeto.

I) Os estudos referidos apontam que a moral pode ser integrada ao self por meio de princípios de conduta, interesses comunitaristas, esquemas, ideais de vida, eventos autobiográficos, entre outros conteúdos. Em nossa concepção é possível sintetizar as diversas proposições na afirmação de que o que se integra ao self são valores morais, entendidos como ideais de vida, princípios de conduta, normas e demais referências de regulação da vida social que expressam conteúdos morais aos quais o sujeito atribui valor e os quais adota como diretriz para a condução da vida que se quer levar e para a construção da pessoa que se deseja ser (Payá, 2010, Puig, 1998).

Afirmar que o que se integra ao self e à identidade são valores morais significa admitir que um self moral pode ser constituído por diferentes tipos de valores morais e que esses podem variar em relação à centralidade com que se integram, seja em um mesmo indivíduo ou entre indivíduos diferentes. Estudos que elegem a priori um conjunto restrito de valores morais para medir sua centralidade por meio de escalas - abordagem majoritária (Hertz \& Krettenauer, 2016) - acabam subdimensionando essas diferenças intra e interindividuais e desconsideram outros valores morais que poderiam ser centrais para os sujeitos.

Além das variações relativas aos tipos de valores morais, interessa-nos sublinhar que tais valores podem se integrar ao self e se expressar de variadas formas. Concordamos com a ideia de Jennings et al. (2015) de que o self moral é um sistema que comporta não apenas ou exclusivamente os traços morais que o sujeito elege para descrever seus atributos pessoais, segundo a vertente dominante (Hertz \& Krettenauer, 2016), mas outras formas de expressão. Consideramos que valores morais podem comparecer na representação de si expressos em objetivos, interesses e projetos de vida (Colby \& Damon, 1992; Frimer \& Walker, 2009); princípios formais, normas e ideologias (Blasi, 2004; Moshman, 2011); protótipos de conduta e scripts de 
ação moral (Lapsley \& Narvaez, 2004); traços morais da identidade social (Aquino \& Reed, 2002); ideal de si moral (Hardy et al., 2014); crenças e juízos morais que admitimos como parte de quem somos (Blasi, 1995; Jennings et al., 2015); emoções morais que nos definem (empatia e compaixão) e que regulam nossa autoestima e nossas ações (culpa e vergonha) (Araújo, 2007; Hardy, 2006; Kristjánsson, 2009; La Taille, 2006); além de eventos biográficos de caráter moral, que incluem ações morais e imorais das quais fomos expectador, agente ou objeto (Blasi, 2004; Lapsley, 2010; Pratt et al., 2009).

Apesar da maior parte dos estudos privilegiar uma ou outra forma de integração, preconizamos a ampliação de estudos que visem abarcar as variações relativas aos tipos de valores morais e às suas diferentes formas de integração ao self, tal como feito por Silva (2020).

II) A formação do selfe da identidade moral é um fenômeno que tem sido explicado de diferentes maneiras. Há, entre os estudiosos do self moral, um consenso de que a integração entre os sistemas do self e da moral passa a ocorrer de modo sistemático e consciente somente a partir da adolescência e que é no final desse período e no início da idade adulta que se configuram as condições para a formação de uma identidade moral mais madura e estável. A construção de um self ou identidade moral está sujeita a múltiplos fatores individuais e sociais, entre eles: a assimilação, já na infância, de esquemas morais à memória biográfica e à personalidade, fruto das orientações de cuidadores e das trocas afetivas estabelecidas com eles (Lapsley \& Narvaez, 2004; Lapsley, 2010); a assimilação dos guias de valor de dada cultura por meio do envolvimento em práticas morais (Puig, 1998); a construção de conhecimentos e concepções morais que o sujeito internaliza como parte de si (Blasi, 1984); a realização de ações morais ou imorais por meio das quais o sujeito se reconhece como um agente moral (Colby \& Damon, 1992; Lapsley, 2010; Pratt, Hunsberger, Pancer, \& Alisat, 2003; Yates \& Youniss, 1996); a coordenação entre interesses individuais e morais como solução adaptativa para o conflito entre tais motivações (Frimer \& Walker, 2009); a exploração de papéis, crenças, ideologias e valores disponíveis no meio cultural pelo jovem como forma de se inserir no mundo adulto e de conferir unidade e propósito a sua identidade (Marcia, 1966; Damon, 1984; Moshman, 2011); e a identificação com os valores e práticas de determinado grupo social (Aquino \& Reed, 2002; Moshman, 2011).

Seja por essas ou outras formas, a construção de valores morais e sua integração ao self dependerá do estabelecimento de vínculo afetivo com conteúdos morais e da compreensão desses como importantes reguladores da vida moral, de modo que o sujeito os aprecie, reconheça-os como importantes para sua vida e se identifique com eles, desejando ser e agir conforme tais conteúdos (Araújo, 2007; Blasi, 1995). A maior ou menor centralidade de um valor moral no sistema de valores dependerá não só da intensidade das projeções afetivas mobilizada na relação entre o sujeito e o objeto de valoração (Araújo, 2007), mas também do acúmulo de experiências, da frequência com que determinado objeto é alvo de tais projeções e da integração que estabelece com outros valores do sistema, sobretudo aqueles dotados de maior centralidade (Silva, 2020).

Convém observar, ainda, que o ato de valorar sempre carrega em si o paradoxo da desaprovação de seu contrário, de tal sorte que um valor moral se integra ao self simultaneamente como valor e seu contravalor.

III) A última consideração que gostaríamos de destacar gira em torno do debate sobre a estabilidade e consistência do self moral em função da variação de contextos e da passagem do tempo. O self, devido ao seu papel de organizador da experiência do sujeito no mundo e provedor do senso de unidade, permanência e individualidade, é um constructo que mantém certa estabilidade. Apesar de sofrer mudanças no curso do desenvolvimento humano, essas ocorrem mais de modo gradual do que abrupto (Harter, 2012). O self moral, por sua vez, também indica obedecer a essa lógica, uma vez que também os valores tendem à conservação temporal (Piaget, 1953/2014) ao serem integrados à estrutura da identidade.

Não obstante, do ponto de vista da influência do self moral sobre os juízos e ações, diversos pesquisadores têm destacado que o sistema de valores possui um funcionamento dinâmico, podendo se reconfigurar de acordo com mudanças contextuais, de tal maneira que um valor pode perder ou ganhar centralidade em relação a outros valores a depender da situação, das pessoas, entre outras variáveis com as quais o sujeito interage (Araújo, 2007; Aquino et al., 2009; Jennings et al., 2015; Lapsley \& Stay, 2014; Nisan, 1993). Para esses pesquisadores, não é possível prever a plena coerência entre um valor e uma ação em diferentes contextos, pois estes exigem e mobilizam diferentes dimensões da personalidade e da identidade.

Por outro lado, outros autores, como Blasi (1995), Lapsley e Narvaez (2004) e Frimer at al. (2011), concordam que quanto maior é a centralidade de um valor para a identidade, maior será sua tendência à estabilidade no self e sua influência sobre os juízos, sentimentos e ações.

Cumpre registrar que o tema da estabilidade $x$ instabilidade e conservação $x$ mudanças no self moral, apesar de fomentar profundo debate teórico, tem sido pouco investigado empiricamente, havendo predomínio de pesquisas em corte transversal em detrimento de pesquisas longitudinais (Hertz \& Krettenauer, 2016; Jennings et al., 2015).

\section{Considerações finais}

A sistematização de diferentes perspectivas sobre self moral permitiu-nos não somente evidenciar suas diferenças, convergências e lacunas, mas também integrar suas diferentes aportações e formular proposições, 
extraindo uma síntese que articula e dá visibilidade a diferentes aspectos do self moral: a) a integração e centralidade de conteúdos morais para o self constitui um importante componente do funcionamento moral, atuando como regulador de juízos e emoções e como motivador de ações morais; b) a integração de valores ao self passa a ocorrer de modo consciente e sistemático a partir da adolescência, sendo a identidade moral sua versão mais elaborada; c) o sistema de valores integrado ao self é aberto e dinâmico, podendo sofrer rearranjos no âmbito de seus conteúdos e organização, em virtude de mudanças de contexto, da aquisição de conhecimentos, em suas condições emocionais, entre outros fatores; porém, quanto maior for a centralidade de valores, menor é sua suscetibilidade às variações temporais e circunstanciais; $d$ ) os valores morais podem ser integrados de múltiplas formas; não somente como traços da identidade social - vertente adotada pela maior parte dos estudos empíricos.

Ao formular essa síntese, esse estudo evidencia o caráter multidimensional do self moral e aponta para a possibilidade de estudos que integrem diferentes manifestações de seu funcionamento e ampliem o espectro de análise sobre esse constructo.

Cumpre observar que a revisão da literatura (Hertz \& Krettenauer, 2016; Silva, 2020) indica a predileção por abordagens quantitativas em corte transversal, que recorrem a escalas como instrumento de aferição da centralidade de valores morais para o self. Tal constatação aponta para a necessidade de ampliação de estudos qualitativos e em corte longitudinal, direcionados, tal como explorado por Silva (2020), a investigar como valores morais são integrados ao self (seus conteúdos, significados e formas de integração), bem como as conservações e mudanças operadas nesse processo de integração ao longo do tempo e em diferentes contextos.

Diante da atual conjuntura, em que valores como a justiça social, a diversidade e a democracia têm sido descreditados e violados, é imperiosa a ampliação de estudos que nos auxiliem, enquanto sociedade, a compreender o funcionamento moral e, consequentemente, a subsidiar a formação de sujeitos e instituições comprometidos com os referidos valores.

\section{Moral self and moral identity: integration between perspectives}

Abstract: Augusto Blasi, Damon and Colby's moral self theories constituted a turning point in the field of moral psychology, in which predominated Kohlberg's perspective. The proposition that the integration between morality and the self or the identity is a fundamental component of moral functioning, inaugurated a new current of studies permeated by different perspectives on moral self functioning and its relationship with moral judgments, emotions and actions. This article systematizes perspectives on the moral self and moral identity constructs, highlighting their differences, convergences and gaps. Furthermore, it proposes an integration between these perspectives and makes contributions that indicate the possibility of expanding the spectrum of understanding about these constructs.

Keywords: moral self, values, moral identity.

\section{Soi-même moral et identité moral: intégration entre perspectives}

Résumé: Les théories sur le soi-même moral formulées par Blasi, Damon et Colby ont constitué un tournant dans le domaine de la psychologie morale, marqué jusque-là par la prédominance de la perspective de Kohlberg. La proposition selon laquelle l'intégration entre la morale et le soi-même ou à l'identité est une composante fondamentale du fonctionnement moral, a inauguré un nouveau courant d'études marqué par différentes perspectives sur le fonctionnement du soi-même moral et sa relation avec les jugements, émotions et actions moraux. Cet article systématise les perspectives sur les concepts soimême morale et identité morale, en soulignant leurs différences, leurs convergences et leurs lacunes. En outre, il propose une intégration entre ces perspectives et apporte des contributions qui indiquent la possibilité d'élargir le spectre de la compréhension de ces concepts.

Mots-clés: soi-même moral, valeurs, identité moral.

\section{Self moral y identidad moral: integración entre perspectivas}

Resumen: Las teorías sobre el self (si mismo) moral formuladas por Blasi, Damon y Colby constituyeron un punto de inflexión en el campo de la psicología moral, hasta ahora marcado por el predominio de la perspectiva de Kohlberg. La proposición de que la integración entre la moral y el self o la identidad es un componente fundamental del funcionamiento moral, inauguró una nueva corriente de estudios con diferentes perspectivas sobre el funcionamiento del self moral y su relación con los juicios, 
las emociones y las acciones morales. Este artículo sistematiza perspectivas sobre las construcciones del selfy identidad moral, destacando sus diferencias, convergencias y lagunas. Además, propone una integración entre estas perspectivas y realiza contribuciones que indican la posibilidad de ampliar el espectro de comprensión sobre eses constructos.

Palabras clave: self moral, valores, identidad moral.

\section{Referências}

Aquino, K., Freeman. D., Reed, A., Felps, W., \& Lim, V. K. G. (2009). Testing a social-cognitive model of moral behavior: The interactive influence of situations and moral identity centrality. Journal of Personality and Social Psychology, 97(1), 123-141. doi: 10.1037/a0015406

Aquino, K., \& Reed, A. (2002). The self-importance of moral identity. Journal of Personality and Social Psychology, 83(6), 1423-1440. doi: 10.1037/0022-3514.83.6.1423

Araújo, U. F. A. (2007). Construção social e psicológica dos valores. In V. A. Arantes (Org.), Educação e valores: Pontos e contrapontos (pp. 17-64). São Paulo, SP: Summus.

Blasi, A. (1983). Moral cognition and moral action: A theoretical perspective. Developmental Review, 3(2), 178-210. doi: 10.1016/0273-2297(83)90029-1

Blasi, A. (1995). Moral understanding and moral personality: The process of moral integration. In W. M. Kurtines \& J. L. Gewirtz (Orgs.), Moral development: An introduction (pp. 229-254). Boston: Allyn \& Bacon.

Blasi, A. (2004). Moral functioning: moral understanding and personality. In D. K. Lapsley \& D. Narvaez (Eds.), Moral development, self, and identity (pp. 335-347). London: Psychology Press.

Colby, A., \& Damon, W.(1992). Some do care: Contemporary lives of moral commitment. New York: Free Press.

Cox, K., \& McAdams, D. P. (2012). The transforming self: Service narratives and identity change in emerging adulthood. Journal of Adolescent Research, 27(1), 18-43. doi: 10.1177/0743558410384732

Damon, W. (1984). Self-understanding and moral development from childhood to adolescence. In W. M. Kurtines \& J. L. Gewirtz (Eds.), Morality, moral behavior and moral development (pp. 109-127). Hoboken: Willey.

Frimer, J. A., \& Walker, L. J. (2009). Reconciling the self and morality: an empirical model of moral centrality development. Developmental Psychology, 45(6), 1669-1681. doi: 10.1037/a0017418

Frimer, J. A., Walker, L. J. Dunlop, W., L., Lee, B. H., \& Riches, A. (2011). The integration of agency and communion in moral personality: evidence of enlightened self-interest. Journal of Personality and Social Psychology, 101(1), 149-163. doi: 10.1037/a0023780

Gilligan, C. (1985) La moral y la teoría: Psicología del desarrollo femenino. Ciudad de Mexico: Fondo de Cultura Económica.

Hardy, S. A. (2006). Identity, reasoning, and emotion: An empirical comparison of three sources of moral motivation. Motivation and Emotion, 30, 205-213. doi: 10.1007/s11031-006-9034-9

Hardy, S. A., \& Carlo, G. (2011). Moral identity: what is it, how does it develop, and is it linked to moral action? Child Development Perspectives, 5(3), 212-218. doi: 10.1111/j.1750-8606.2011.00189.x

Hardy, S. A., Walker, L. J., Olsen, J. A., Woodbury, R. D., \& Hickman, J. R. (2014). Moral identity as moral ideal self: Links to adolescent outcomes. Developmental Psychology, 50(1), 45-57. doi: 10.1037/a0033598

Harter, S. (2012). The construction of the self: Developmental and sociocultural foundations. New York: Guilford Publications.

Hertz, S. G., \& Krettenauer, T. (2016). Does moral identity effectively predict moral behavior? A Meta-Analysis. Review of General Psychology, 20(2), 129-140. doi: $10.1037 / \mathrm{gpr} 0000062$

Hoffman, M. L. (1990). The contribution of empathy to justice and moral judgment. In N. Eisenberg \& J. Strayer, Empathy and its development (pp. 47-79). New York: Cambridge University Press.

Jennings, P. L., Mitchell, M. S., \& Hannah, S. T. (2015). The moral self: A review and integration of the literature. Journal of Organizational Behavior, 36(51), 104-168. doi: 10.1002/job.1919

Kohlberg, L. (1989). Estadios morales y moralización: El enfoque cognitivo-evolutivo. In E. Turiel, L. Enesco, \& J. Linaza (Orgs.), El mundo social en la mente infantil. Madrid: Alianza Editorial.

Kristjánsson, K. (2009). Putting emotion into the self: A response to the 2008 Journal of Moral Education special issue on moral functioning. Journal of Moral Education, 38(3), 255-270. doi: 10.1080/03057240903101374

La Taille, Y. (2006). Moral e ética: dimensões intelectuais e afetivas. Porto Alegre, RS: Artmed.

Lapsley, D. K. (2010). Moral agency, identity and narrative in moral development: Commentary on Pasupathi and Wainryb. Human Development, 53(2), 87-97. doi: $10.1159 / 000288210$

Lapsley, D. K., \& Hill, P. L. (2009). The development of the moral personality. In D. Narvaez \& D. K. Lapsley (Eds.), Personality, identity, and character: Explorations in moral psychology (pp. 185-213). New York: Cambridge University Press.

Lapsley, D. K., \& Narvaez, D. (2004). A social-cognitive approach to the moral personality. In: D. K. Lapsley \& 
D. Narvaez (Eds.), Moral development, self, and identity (pp. 189-212). London: Psychology Press.

Lapsley, D. K., \& Stay, P. (2014). Moral self-identity as the aim of education. In L. Nucci \& D. Narvaez (Eds.), Handbook of moral and character education. Abingdon: Routledge.

Marcia, J. E. (1966). Development and validation of egoidentity status. Journal of Personality and Social Psychology, 3(5), 551-558. doi: 10.1037/h0023281

Mallin, H., Ballard, P. J., \& Damon, W. (2015). Civic purpose: An integrated construct for understanding civic development in adolescence. Human Development, 58(2), 103-130. doi: 10.1159/000381655

McAdams, D. P. (2009). The moral personality. In D. Narvaez \& D. K. Lapsley (Eds.), Personality, identity and character: Explorations in moral psychology (pp. 11-29). New York: Cambridge University Press.

Moshman, D. (2011). Adolescent rationality and development: Cognition, morality, and identity (3a ed.). Abingon: Taylor \& Francis.

Nisan, M. (1993). Balanced identity: Morality and other identity values. In G. Noam \& T. Wren (Eds.), The moral self (pp. 239-266). Cambridge: MIT Press.

Nisan, M. (2004). Judgment and choice in moral functioning. In D. K. Lapsley \& D. Narvaez (Eds.), Moral development, self, and identity (pp. 133-160). London: Psychology Press.

Nucci, L. (1996). Morality and the personal sphere of action. In E. S. Reed, E. Turiel, \& T. Brown (Eds.), Values and knowledge (pp. 41-60). London: Psychology Press.

Payá, M. (2010). El proceso de construcción de valores. In J. M. Puig (Coord.), Entre todos: Compartir la educación para la ciudadanía (pp. 33-46). Barcelona: Horsori Editorial.

Piaget, J. (2014). Relações entre a afetividade e a inteligência no desenvolvimento mental da criança. Rio de Janeiro, RJ: Wak. (Trabalho original publicado em 1953).
Pratt, M. W., Arnold, M. L., \& Lawford, H. (2009). Growing towards care: a narrative approach to prosocial moral identity and generativity of personality in emerging adulthood. In D. Narvaez \& D. K. Lapsley (Eds.), Personality, identity, and character: Explorations in moral psychology (pp. 295-315). New York: Cambridge University Press.

Pratt, M. W., Hunsberger, B., Pancer, M. S., \& Alisat, S. (2003). A longitudinal analysis of personal values socialization: Correlates of a moral self-ideal in late adolescence. Social Development, 12(4), 563-585. doi: 10.1111/1467-9507.00249

Puig, J. M. (1998). A construção da personalidade moral. São Paulo, SP: Ática.

Reed, A., Kay, A., Finnel, S., Aquino, K., \& Levy, E. (2016). I don't want the money, I just want your time: How moral identity overcomes the aversion to giving time to prosocial causes. Journal of Personality and Social Psychology, 110(3), 435-457. doi: 10.1037/pspp0000058

Silva, M. A. M. (2020). Integração de valores morais às representações de si de adolescentes. [Tese de Doutorado, Universidade de São Paulo].

Turiel, E. (1989). Dominios y categorias en el desarollo cognitivo y social. In E. Turiel, L. Enesco, \& J. Linaza (Orgs.), El mundo social en la mente infantil (p. 37-70). Madrid: Alianza editorial.

Turiel, E. (1996). Equality and hierarchy: Conflict in values. In: E. S. Reed, E. Turiel, \& T. Brown (Eds.), Values and knowledge (pp. 75-101). London: Psychology Press.

Yates, M. A., \& Youniss, J. (1996). A developmental perspective on community service in adolescence. Social Development, 5(1), 85-111. doi: 10.1111/j.1467-9507.1996.tb00073.x

Recebido 9/04/2020

Revisado 14/10/2020

Aprovado 22/10/2020 